\title{
Correspondence
}

Irish Journal of Psychological Medicine, 38 (2021).

doi:10.1017/ipm.2021.23

Personal and social changes in the time of COVID-19

\section{Setting the scene}

Coronavirus disease (COVID-19) has been one of the most powerful and lasting realities of 2020. Its impact at social and personal levels cannot be understated. The second and third peak of infections have been registered in all the countries, and authorities (governments and healthcare agencies) are struggling with new local, regional or national lockdowns in order to contain the spreading of the virus; also intervention plans have been adopted to reallocate resources for the pandemic-related economic crisis (WHO, 2020a).

The World Health Organization has warned a mental health burden related to the spreading of COVID-19 infection through the global population: stress, worry, fear, changes in our daily lives (home working, temporary unemployment, homeschooling, etc.) are all challenging people's mental and physical health as well as the global healthcare system and economy (WHO, 2021).

\section{Changes at personal level}

Feelings of uncertainty, confusion, fear and loneliness have been reported at a personal level (Torales et al. 2020a; Ventriglio et al. 2020a), with an increase in adjustment disorders as well as anxiety and depression (Torales et al. 2020b). A sense of personal insecurity is likely to cause a psychological reaction to the pandemic as a majority of people may perceive themselves as vulnerable or potentially at risk of contracting the virus. It may be challenging to reframe the human psyche to a new normal life: Seligman's construct of synergistic impact of the loss of control and rising uncertainty may explain the rising public mental health issues, but also positive psychologists may suggest a shift from pessimism and gloom to hope and optimism, with a settlement on endurance and resilience (Gibbon, 2020).

It has been widely described that changes in lifestyle due to the quarantine, in particular changes in sleeping and eating patterns, are significantly associated with increase of stress and mood disorders among the general population as well as patients affected by preexisting mental illness (Gentile et al.
2020). Also, behavioral consequences of the pandemic have included an increase in substance abuse, in particular alcohol drinking within the home (Torales et al. 2020b), or substance abuse in lower income groups: these behaviors may increase the viral contamination among those subjects who are vulnerable to their own clinical and psychosocial conditions; in addition, the access to treatment for substance abusers has been limited by the emergency resulting in a worsening of their outcomes (Ornell et al. 2020).

It has been argued that individuals may also develop paranoid feelings and worries about being seen as infectious (Ventriglio et al. 2020a). Long periods of personal distancing and lockdown have influenced the way people enter into relationships with others: a lack of social and emotional closeness may lead to psychological distress, an increase of paranoid attitudes as well as feelings of loneliness and hopelessness (Ventriglio et al. 2020a; Ventriglio et al. 2020b). Also, since personal distancing involves families, close friends, peers and colleagues, a remarkable change in the daily routine and social support will be felt. The current pandemic has also modified personal lifestyles: people are wearing masks most of the day, are following hygiene-sanitary norms while working, shopping, traveling and so on, are avoiding handshakes, hugs, kisses and socializing. Moreover, leisure activities have also been affected, for example, going to the gymnasium has been replaced by outdoor or home sports activity, cinemas and theaters as well as any other public events have been restricted, group- and sociocultural activities limited by the need for increased levels of hygiene (Ventriglio et al. 2020b). The subjective/collective perception of limited individual rights has led to libertarian responses to personal restrictions (Ventriglio et al. 2020b).

Increasing evidence report neuropsychiatric consequences of COVID-19 at an individual level. Recently, a UK surveillance study reported on neurological and psychiatric complications of COVID-19 among 153 patients: $62 \%$ of them reported cerebrovascular events (e.g. stroke, intracerebral hemorrhage and 31\% altered mental status) (Varatharaj et al. 2020). Also, there is a growing concern regarding the long COVID-19 syndrome, characterized by prolonged multi-organ symptoms beyond the acute phase of illness including persistent cough, short breath, cognitive dysfunction and physical fatigue. The National Institute of Clinical Excellence (NICE) has delivered clinical guidelines for the follow-up and management of persisting symptoms among affected patients (Venkatesan, 2021). 


\section{Changes at societal levels}

Societies around the globe have been heavily affected by COVID-19. The economic burden of the pandemic has been phenomenal. It has led to a reduction in the Gross Domestic Product (GDP), national incomes as well as a consequent rise in levels of unemployment (Pak et al. 2020). Healthcare systems are overburdened due to an increasing demand for physical and mental health care (Cash \& Patel, 2020). Concerns about mental illness health have been warned by the WHO months ago (WHO, 2020a). Education (primary and secondary school, university) has been affected by the pandemic at many levels (WHO, 2020b; UNESCO, 2020): most of learning and teaching have been converted into remote education with the employment of online platforms and technology; the long-term impact on children, their learning and well-being are unpredictable (Power et al. 2020). Also, the social perception of limited rights (including work, leisure, education, health care, etc.) has led to collective behaviors and ideology of nonacceptance with a widespread denialism (Rohde, 2020). Social media plays a role in spreading various conspiracy theories, for example, the supposed man-made origin of the virus (created for putative international economic or political purposes), global distraction strategy aimed to hide an international secret agenda (such as the development and dissemination of $5 \mathrm{G}$ antennas) or the promotion of a global controlling vaccination campaign (Rohde, 2020; Ventriglio et al. 2020b). We may argue that denialists and antivaxxers represent a collective response of some groups of the population, mainly based on cultural or subcultural beliefs, to a traumatic experience affecting everyone's life (Ventriglio et al. 2020b).

It is also crucial that the COVID-19 pandemic is exacerbating social inequalities. Marmot in his review of COVID-19 entitled Build Back Fairer has reported emerging concern about inequalities in mortality among minorities such as Black, Asian, and Minority Ethnic(BAME) and in deprived areas. There is an urgent need for governmental interventions aimed to reduce inequalities in public health, mortalities and socioeconomic support during the pandemic: mental health services need to deal with the post-COVID-19 burden, promote peer support, voluntary activities as well as community interventions based on primary care surveillance and low cognitive behavioral support on a large scale (Marmot \& Allen, 2020).

\section{Actions needed}

It is critical that an internationalist approach is needed as more vaccines become available. The governments must provide support:
- at personal level: (a) people affected by COVID-19 with dedicated psychological support in the hospitals as well as (phone-) helplines for those in the at-home setting; (b) the frontline healthcare professionals in the fight against the virus; (c) psychoeducational messages delivered by media in order to provide correct information and regular updates regarding the infection and strategies to cope with restrictions and isolation and (d) positive and hopeful messages.

- at social level: (a) timely emergency provisions should be adopted to deploy the health network and COVID-19 hospitals; (b) extraordinary funds should be provided to support categories afflicted by the pandemic (recovery funds); (c) timely provisions to deploy tele-education where needed and (d) awareness-raising campaigns should be conducted to challenge denialism and aimed to increase the level of social responsibility.

It is becoming clearer that the recipe against COVID-19 is based on personal and social responsibility.

\section{Acknowledgments}

None.

\section{Financial support}

None.

\section{Conflict of interest}

The authors have no conflicts of interest to declare.

\section{Ethical standards}

The manuscript has been drafted according to the ethical standards in research. It does not report on clinical or experimental data so no Ethical approval was necessary.

\section{References}

Cash R, Patel V (2020). Has COVID-19 subverted global health? Lancet Psychiatry 395, 1687-1688.

Gentile A, Torales J, O'Higgins M, Figueredo P, Castaldelli-Maia JM, De Berardis D, Petito A, Bellomo A, Ventriglio A (2020). Phone-based outpatients' followup in mental health centers during the COVID-19 quarantine. International Journal of Social Psychiatry. 9, 20764020979732. doi:10.1177/0020764020979732. Epub ahead of print. PMID: 33295245; PMCID: PMC7726626.

Gibbon P (2020). Martin seligman and the rise of positive psychology. Humanities 41, 3 (https: / / www.neh.gov/ article/martin-seligman-and-rise-positive-psychology). Accessed 7 November 2020. 
Marmot M, Allen J (2020). COVID-19: exposing and amplifying inequalities. Journal of Epidemiology and Community Health 74, 681-682.

Ornell F, Ferreira Moura H, Nichterwitz Scherer J, Pechansky F, Felix Paim Kessler H, von Diemen L (2020). The COVID-19 pandemic and its impact on substance use: implications for prevention and treatment. Psychiatry Research 289, 113096.

Pak A, Adegboye OA, Adekunle AI, Rahman KM, McBryde ES, Eisen DP (2020). Economic consequences of the COVID-19 outbreak: the need for epidemic preparedness. Frontiers in Public Health 8, 241.

Power E, Hughes S, Cotter D, Cannon M (2020). Youth mental health in the time of COVID-19. Irish Journal of Psychological Medicine 37, 301-305.

Rohde D (2020). Conspiracy theories, denial, and the coronavirus. New Yorker (https://www.newyorker.com/ news/daily-comment/conspiracy-theories-denial-and-thecoronavirus). Accessed 7 November 2020.

Torales J, O'Higgins M, Castaldelli-Maia JM, Ventriglio A (2020a). The outbreak of COVID-19 coronavirus and its impact on global mental health. International Journal of Social Psychiatry 66, 317-320.

Torales J, Ríos-González C, Barrios I, O'Higgins M, González I, García O, et al. (2020b). Self-perceived stress during the quarantine of COVID-19 pandemic in Paraguay: an exploratory survey. Frontiers in Psychiatry 11, 558691.

UNESCO (2020). Education: from disruption to recovery (https://en.unesco.org/covid19/educationresponse). Accessed 7 November 2020.

Varatharaj A, Thomas N, Ellul MA, Davies, N, Pollak, TA, Tenorio, EL, et al. (2020). Neurological and neuropsychiatric complications of COVID-19 in 153 patients: a UK-wide surveillance study. The Lancet Psychiatry 7, 875-882.

Venkatesan P (2021). NICE guideline on long COVID. The Lancet Respiratory Medicine 9, 129.

Ventriglio A, Bellomo A, Joseph SJ, Bhugra D (2020b). Post-outbreak psychosocial "needs" of the public in the COVID-19 era. Open Journal Psychiatry and Allied Sciences (OJPAS) 12, 62-64.

Ventriglio A, Watson C, Bhugra D (2020a). Pandemics, panic and prevention: stages in the life of COVID-19 pandemic. International Journal of Social Psychiatry 66, 733-734.

World Health Organization (2020a). Coronavirus disease (COVID-19). Situation report-200 (https://www.who.int/ publications/m/item/weekly-epidemiological-update10-november-2020). Accessed 7 November 2020.

World Health Organization (2020b). Key messages and actions for COVID-19 prevention and control in schools (https://www.who.int/docs/default-source/coronaviruse/ key-messages-and-actions-for-covid-19-prevention-andcontrol-in-schools-march-2020.pdf?sfvrsn=baf81d52_4\& gclid=CjwKCAjwmrn5BRB2EiwAZgL9oqqMJnnPZTYNJvAKGgKXqroOwFrBp5BInEFd0QtPkib3tI8yUulxoCUhUQAvD_BwE). Accessed 7 November 2020.

World Health Organization (2021). Mental health \& COVID-19 (https: / / www.who.int/teams/mental-healthand-substance-use/covid-19). Accessed 7 November 2020.

\section{A. Ventriglio}

Department of Clinical and Experimental Medicine, University of Foggia, Foggia, Italy

(Email: a.ventriglio@libero.it)

\section{J. M. Castaldelli-Maia}

Department of Neuroscience, Medical School, Fundação do ABC, Santo André, SP, Brazil

Department of Psychiatry, Medical School, University of São Paulo, São Paulo, SP, Brazil

\section{J. TORALES}

Department of Psychiatry, School of Medical Sciences, National University of Asunción, Asunción, Paraguay

\section{E. M. Chumakov (iD}

St. Petersburg Psychiatric Hospital № 1 named after P.P. Kaschenko, St. Petersburg State University, Saint-Petersburg, Russia

D. BHUGRA

Institute of Psychiatry, King's College, London, UK 